\title{
Effect of Caffeine Injection on Orthodontic Tooth Movement in Rats: An Experimental Study on Rats
}

\author{
Amin Golshah $\mathbb{D}^{1},{ }^{1}$ Khaled Omidi $\mathbb{D}^{2},{ }^{2}$ Nafiseh Nikkerdar $\mathbb{D}^{3},{ }^{3}$ and Fatemeh Ghorbani $\mathbb{D}^{1,4}$ \\ ${ }^{1}$ Department of Orthodontic, School of Dentistry, Kermanshah University of Medical Sciences, Kermanshah, Iran \\ ${ }^{2}$ Student Research Committee Kermanshah University of Medical Sciences, Kermanshah, Iran \\ ${ }^{3}$ Department of Maxillofacial Radiology, School of Dentistry, Kermanshah University of Medical Sciences, Kermanshah, Iran \\ ${ }^{4}$ Medical Biology Research Center, Health Technology Institute, Kermanshah University of Medical Sciences, Kermanshah, Iran \\ Correspondence should be addressed to Fatemeh Ghorbani; tima.ghorbani@gmail.com
}

Received 1 August 2021; Revised 28 September 2021; Accepted 9 January 2022; Published 25 January 2022

Academic Editor: Li Wu Zheng

Copyright (c) 2022 Amin Golshah et al. This is an open access article distributed under the Creative Commons Attribution License, which permits unrestricted use, distribution, and reproduction in any medium, provided the original work is properly cited.

\begin{abstract}
Objectives. Several studies have investigated the effects of different medications on orthodontic tooth movement (OTM). This study assessed the effect of caffeine injection on OTM in rats. Materials and Methods. Thirty-five male Wistar rats were randomly divided into five groups. Their first molars and central incisors were attached with a nickel-titanium closed coil spring with $50 \mathrm{~g}$ load. The rats in the three experimental groups received 25,50 , and $75 \mathrm{mg} / \mathrm{kg}$ caffeine intraperitoneally for 21 days. The negative control group did not receive any injection and did not undergo orthodontic treatment. The positive control group underwent orthodontic treatment and received $0.9 \% \mathrm{NaCl}$ (saline) injection. After 21 days, all rats were sacrificed by chloroform inhalation, and the maxilla was resected. The mean number of Howship's lacunae, blood vessels, osteoclasts, and root resorption lacunae was histologically measured. The bone volume-to-total volume ratio (BV/TV) in maxillary molars was calculated by microcomputed tomography (micro-CT) to quantify bone loss. Results. The amount of OTM and the number of osteoclasts, blood vessels, and Howship's lacunae significantly increased in rats under caffeine therapy, while the number of root resorption lacunae did not increase. Lower BV/TV in the caffeine groups was in accord with the increased count of osteoclasts. Conclusion. Caffeine injection can significantly increase OTM in rats.
\end{abstract}

\section{Introduction}

Orthodontic treatment has gained wide public acceptance in the recent years. It not only corrects dental anomalies but also improves the esthetic appearance of the face. Moreover, orthodontic treatment corrects temporomandibular joint disorders due to malocclusion [1]. Orthodontic tooth movement (OTM) is induced by mechanical stimuli and enhanced by the periodontal ligament and alveolar bone remodeling [2,3]. Mechanical loads induce the local cellular responses in the periodontal ligament and alveolar bone and enable OTM $[4,5]$. Bone remodeling is a dynamic process that occurs following the interactions of bone-forming osteoblasts and bone-resorbing osteoclasts $[2,6]$. Orthodontic forces can increase the intracellular secondary messengers, which are critical for osteoblastic differentiation and OTM
[7]. Thus, theoretically, any factor affecting the osteoclastic function can affect the OTM as well $[8,9]$. To shorten the treatment course, orthodontists have long been in search of methods to accelerate OTM. Also, orthodontists should have adequate information about the medications that can change the bone physiology because they can probably affect the treatment course as well $[10,11]$. Recent evidence confirmed the effect of several systemic factors on OTM. Some medications have an adverse effect on this process and can decelerate the treatment course, while some others can shorten the duration of treatment $[12,13]$.

Caffeine (1,3,7-trimethylxanthine) is among the most common central nervous system stimulants used in drinks, foods, and medications [14, 15]. Caffeine has several activities at the cellular and molecular levels, affecting phosphodiesterase, adenosine receptors, prostaglandins, and 
proinflammatory mediators [4]. Caffeine can lead to osteoclastogenesis through the COX-2/prostaglandin E2 (PGE2) pathway [16]. Consumption of caffeine-containing products may affect the bone metabolism [17]. Since caffeine has various effects on the bone metabolism, it may affect the OTM as well, particularly if consumed on a daily basis [10].

The reports regarding the effects of caffeine on bone metabolism, bone density, and bone regeneration have been controversial. Some authors reported that caffeine caused osteoporosis and periodontal disease $[15,18,19]$, while some others found no significant correlation between bone loss, bone density, or disease conditions with caffeine consumption $[20,21]$. Also, it has been demonstrated that caffeine can positively affect the process of mineralization and enhance the mechanical properties of the skeletal tissue if consumed at certain times [4].

Evidence shows that the genome of rats and humans is highly similar such that approximately $90 \%$ of the human genes have direct orthologs in rats [22]. Thus, we hypothesized that daily injection of caffeine may enhance OTM. Previous studies on this topic mainly evaluated the effects of oral administration of caffeine, and studies regarding the effects of caffeine injection are lacking $[10,15,16]$. Thus, this study aimed to assess the biological and histological effects of the intraperitoneal injection of caffeine on OTM in rats.

\section{Materials and Methods}

2.1. Animal Model and Treatment Methods. The study was approved by the ethics committee of Kermanshah University of Medical Sciences (IR.KUMS.REC.1397.724) and conducted in accordance with the ARRIVE guidelines [23]. This animal study evaluated 35 male Wistar rats weighing 200-250 g (all rats were purchased from Kermanshah University of Medical Sciences). The rats were kept in transparent plastic cages under standard laboratory conditions at a constant temperature of 24$25^{\circ} \mathrm{C}, 55 \%$ humidity, and $12 \mathrm{~h}$ dark $/ 12 \mathrm{~h}$ light cycles for one week prior to the experiment for the purpose of acclimation [24]. The rats were fed soft food to minimize the appliance movement after installation. The orthodontic appliance was installed for all rats except for the negative control group as explained elsewhere [25]. Injections were made at $1,3,5,7,9,11,13,15,17,19$, and 21 days after appliance placement. The rats were randomized into five groups $(n=7)[26,27]$ as follows.

Group 1 received intraperitoneal injection of $25 \mathrm{mg} / \mathrm{kg}$ caffeine at the aforementioned time points for 3 weeks simultaneously with orthodontic treatment.

The rats in group 2 received intraperitoneal injection of $50 \mathrm{mg} / \mathrm{kg}$ caffeine at the aforementioned time points for 3 weeks simultaneously with orthodontic treatment.

The rats in group 3 received intraperitoneal injection of $75 \mathrm{mg} / \mathrm{kg}$ caffeine at the aforementioned time points for 3 weeks simultaneously with orthodontic treatment.

The negative control group did not receive any injection and did not undergo orthodontic treatment. Caffeine was purchased from Sigma-Aldrich (St. Louis, MO, USA).
The rats in the positive control group received intraperitoneal injection of $0.9 \% \mathrm{NaCl}$ at the aforementioned time points for 3 weeks simultaneously with orthodontic treatment.

2.2. Placement of the Orthodontic Appliance. The rats were anesthetized with $10 \%$ ketamine hydrochloride $(50 \mathrm{mg} / \mathrm{kg}$; Alfasan, Woerden, Netherlands) and $2 \%$ xylazine $(2 \mathrm{mg} / \mathrm{kg}$; Alfasan, Woerden, Netherlands). After anesthesia induction, the vital signs of the rats were closely monitored. Also, they were rotated from side to side every couple of minutes to prevent pulmonary edema. The room temperature was also controlled. The nickel-titanium closed coil springs were installed (G\&H Franklin, $6 \mathrm{~mm}, 50 \mathrm{~g}$ ) to induce OTM. The first molars and central incisors were connected by a stainless steel wire. Next, the first molars and central incisors were etched with $37 \%$ phosphoric acid (Vivadent, USA) for $30 \mathrm{~s}$, rinsed for $10 \mathrm{~s}$, and dried with an air spray for $15 \mathrm{~s}$. Single Bond (3M ESPE, St. Paul, MN, USA) was applied on the surface and light-cured with a LED curing unit (Woodpecker, Muenster, Germany) with a light intensity of $150 \mathrm{mw} / \mathrm{cm}^{2}$ for $10 \mathrm{~s}$ followed by the application of Transbond XT composite (3M ESPE, St. Paul, MN, USA).

The load applied by the coil springs was $50 \mathrm{~g}$ [28] (Figure 1). The magnitude of load applied by the coil spring was measured by using a force meter upon installation. To protect the orthodontic appliance, the lower teeth were reduced. The rats were examined daily to ensure the presence of the coil spring at its rightful place. In case of debonding of the appliance, the rat would be excluded and replaced [29].

2.3. OTM. The distance between the enamel of the most distal part of the first molar crown and mesial surface of the second molar was measured by an examiner blinded to the group allocation of rats at baseline and after 21 days. ABViewer 14 software was used for this purpose. Each measurement was repeated 3 times, and the mean of the measurements was reported as the final value. Impressions were made from the teeth at 1 and 21 days using injection silicone polyvinyl siloxane impression material (Express; $3 \mathrm{M}$ Dental Products, St. Paul, MN, USA). After 4 min (to allow polymerization), the impressions were checked and poured with dental stone (Elite Rock Dental Stone; Zhermack, Badia Polesine, Italy). After $24 \mathrm{~h}$, the gypsum cast was removed. The casts were scanned with a 3D scanner (inEos X5; Sirona Dental Systems, Bensheim, Germany) to create 3D models in an STL format [30] (Figure 2). Next, the STL files were sent to ABViewer 14 software for the measurements.

\subsection{Histological and Immunohistochemical Analyses}

2.4.1. Tissue Preparation. After 21 days, the rats were sacrificed by inhalation of chloroform in a desiccator. The maxilla was resected and sent for histological analysis. The specimens were fixed in $10 \%$ formaldehyde and decalcified in $10 \%$ formic acid for $48 \mathrm{~h}$ (Sigma-Aldrich; St. Louis, MO, 


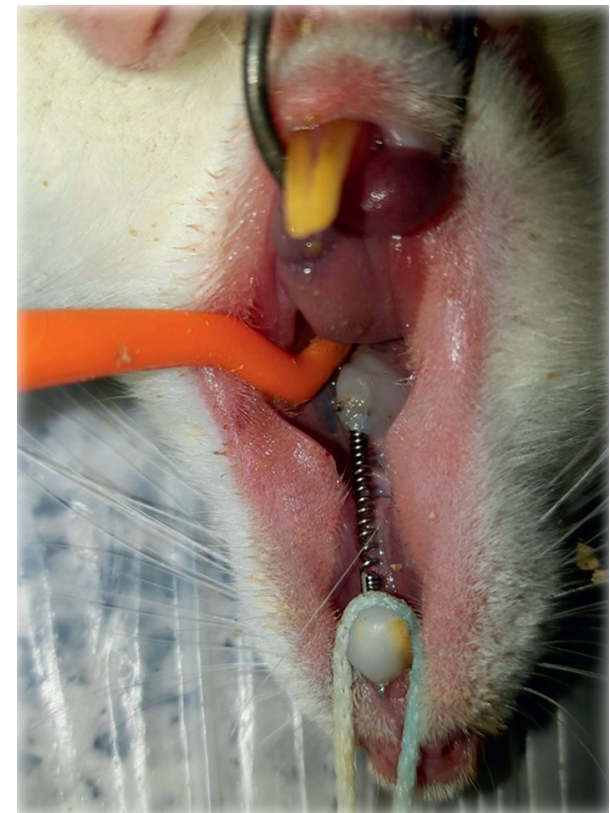

FIGURE 1: Nickel-titanium closed coil spring installed between the first molars and central incisors.

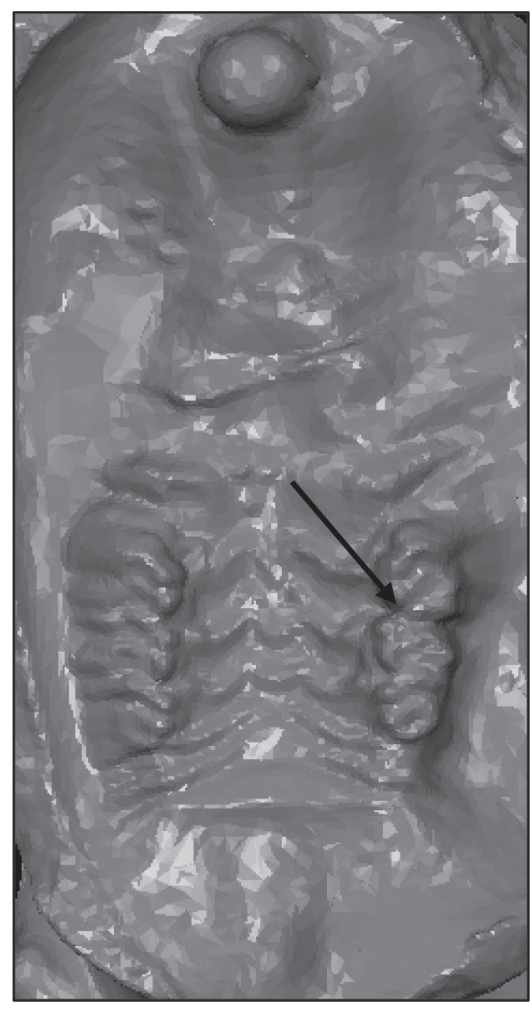

FIGURE 2: Three-dimensional scan of the cast of a rat that received caffeine simultaneously with orthodontic treatment using ABViewer software. The arrow indicates the amount of OTM.

USA). After fixation, decalcification of the tissue was performed using $12.5 \%$ ethylenediaminetetraacetic acid, and fixation was performed by using a fixator for 10 weeks. The decalcifying solution was agitated 10 times a day and refreshed twice weekly until complete decalcification occurred. Next, they were dehydrated by using ethanol and embedded in paraffin blocks. Parasagittal sections were made by using a microtome (Leica, Wetzlar, Germany) with $5 \mu \mathrm{m}$ thickness [31]. An examiner (A. H. Y) who was blinded to the group allocation of specimens performed all the histological analyses.

2.4.2. Histological Assessment. Tissue specimens were stained with hematoxylin and eosin, and the slides were inspected by an experienced pathologist who was blinded to the group allocation of specimens under a light microscope (Eclipse E400, Nikon, Japan) at 100x magnification. The number of Howship's lacunae, blood vessels, osteoclasts, and root resorption lacunae was also counted in an area measuring $0.01 \mathrm{~mm}^{2}$. Each specimen was assessed three times, and the mean of the three measurements was recorded.

2.5. Microcomputed Tomography (Micro-CT) Analysis. In this study, we used an in vivo X-ray microcomputed tomography (micro-CT) scanner. LOTUS-inVivo has a cone beam microfocus X-ray source and a flat panel detector. In order to obtain best possible image quality, the X-ray tube voltage and its current were set to $60 \mathrm{kV}$ and $130 \mu \mathrm{A}$, respectively, and frame exposure time was set to 1 second by 1.4 magnification. Total scan duration was 28 minutes. Slice thicknesses of reconstructed images were set to $50 \mathrm{mi}$ crometers. All the protocol settings were controlled by LOTUS-inVivo-ACQ software. The acquired 3D data were reconstructed using LOTUS-inVivo-REC by a standard Feldkamp, Davis, and Kress (FDK) algorithm. Also, LOTUSinVivo-3D was used for rendering of reconstructed images, and by adding the bone analysis plugin (BAP) inside software, we reported bone volume (BV) and total volume (TV) parameters [32].

2.6. Statistical Analysis. The data were analyzed using SPSS version 21 (IBM, Armonk, NY, USA) by one-way ANOVA, Tukey's test, and $t$-test.

\section{Results}

The minimum intraclass correlation coefficient was calculated to be 0.964 for all variables, indicating excellent reliability of the measurements.

3.1. Effect of Daily Injection of Caffeine on OTM. Figure 2 presents the descriptive data regarding OTM in the five groups. After 21 days of application of orthodontic force, a significant difference was noted among the five groups in OTM $(P<0.05)$. The amount of OTM was minimum in the negative control $(P=0.011)$ and maximum in the $75 \mathrm{mg} / \mathrm{kg}$ caffeine group $(P=0.458)$. A significant difference existed between the negative control group and all other groups in OTM $(P<0.05)$. Also, significant differences existed between the positive control and $50 \mathrm{mg} / \mathrm{kg}$ caffeine and positive control and $75 \mathrm{mg} / \mathrm{kg}$ caffeine groups $(P<0.05)$. However, 
the difference between the positive control and $25 \mathrm{mg} / \mathrm{kg}$ caffeine group was not significant $(P=0.354)$. Increasing the caffeine dosage significantly increased the mean amount of OTM such that the difference between the 25 and $50 \mathrm{mg} / \mathrm{kg}$ $(P=0.005)$ and 25 and $75 \mathrm{mg} / \mathrm{kg}(P<0.05)$ caffeine groups was significant. However, the difference between the 50 and $75 \mathrm{mg} / \mathrm{kg}$ caffeine groups did not reach statistical significance $(P=0.582$, Table 1$)$.

Figure 3 shows the micro-CT images of OTM in the five groups.

3.2. Histopathological Evaluation. Light microscopic findings of the periodontal tissue showed that, in the negative control group, the number of blood vessels and osteoclasts was histologically normal. In the positive control group, which was affected by orthodontic force, the number of blood vessels and osteoclasts increased on average, but this increase was more pronounced in the three groups of caffeine, which were simultaneously affected by orthodontic force and different doses of caffeine (Figure 4).

3.3. Histological Analysis. Table 2 presents the mean and standard deviation of histological variables.

3.4. Howship's Lacunae. At 21 days, a significant difference existed in the number of Howship's lacunae among the five groups $(P<0.05)$. The number of Howship's lacunae was maximum in the $75 \mathrm{mg} / \mathrm{kg}$ caffeine group $(P=4.166)$ and minimum in the negative control group $(P=0.166)$. Significant differences existed between the negative control and all other groups in the number of Howship's lacunae $(P<0.05)$. However, the difference was not significant between the positive control and $25 \mathrm{mg} / \mathrm{kg}$ caffeine groups $(P=0.540)$. The difference between the positive control and $50 \mathrm{mg} / \mathrm{kg}$ caffeine group was not significant either $(P=0.323)$. However, the difference was significant between the positive control and $75 \mathrm{mg} / \mathrm{kg}$ caffeine group $(P<0.05)$. The difference between the 25 and $50 \mathrm{mg} / \mathrm{kg}$ caffeine groups was not significant $(P=0.995)$, but the difference between the 25 and $75 \mathrm{mg} / \mathrm{kg}$ caffeine groups was significant $(P=0.014)$. Also, 50 and $75 \mathrm{mg} / \mathrm{kg}$ caffeine groups had a significant difference in this respect $(P=0.035)$.

3.5. Blood Vessels. At 21 days, a significant difference was noted in the number of blood vessels among the five groups $(P<0.05)$. The number of blood vessels was maximum in $75 \mathrm{mg} / \mathrm{kg}$ caffeine $(P=5.6)$ and minimum in the negative control group $(P=2.0)$. Also, the difference between the negative control group and the other groups was significant $(P<0.05)$. No significant difference was noted between the positive control and $25 \mathrm{mg} / \mathrm{kg}$ caffeine $(P=1.000)$ or positive control and $50 \mathrm{mg} / \mathrm{kg}$ caffeine $(P=0.340)$ groups. However, the difference between the positive control and $75 \mathrm{mg} / \mathrm{kg}$ caffeine group was significant $(P \leq 0.001)$. The difference between the 25 and $50 \mathrm{mg} / \mathrm{kg}$ caffeine groups was not significant $(P=0.340)$, but 25 and $75 \mathrm{mg} / \mathrm{kg}$ caffeine groups
$(P \leq 0.001)$ and 50 and $75 \mathrm{mg} / \mathrm{kg}$ caffeine groups had significant differences in this regard $(P=0.002)$.

3.6. Osteoclasts. A significant difference existed among the five groups in the number of osteoclasts $(P<0.05)$. The number of osteoclasts was maximum in $75 \mathrm{mg} / \mathrm{kg}$ caffeine $(P=4.000)$ and minimum in the negative control group $(P=0.833)$. A significant difference existed between the negative control and the other groups in the number of osteoclasts $(P<0.05)$. No significant difference existed between the positive control and $25 \mathrm{mg} / \mathrm{kg}$ caffeine group $(P=0.139)$. However, the difference between the positive control and $50 \mathrm{mg} / \mathrm{kg}$ caffeine group was significant $(P=0.025)$. A significant difference was also noted between the positive control and $75 \mathrm{mg} / \mathrm{kg}$ caffeine group $(P=0.010)$. No significant difference was found between the 25 and $50 \mathrm{mg} / \mathrm{kg}(P=0.925), 25$ and $75 \mathrm{mg} / \mathrm{kg}(P=0.742)$, or 50 and $75 \mathrm{mg} / \mathrm{kg}$ caffeine groups $(P=0.994)$.

3.7. Root Resorption Lacunae. At 21 days, a significant difference was noted in the number of root resorption lacunae among the five groups $(P<0.05)$. The number of root resorption lacunae was maximum in 50 and $75 \mathrm{mg} / \mathrm{kg}$ caffeine $(P=1.5)$ and minimum in the negative control group $(P \leq 0.01)$. No root resorption lacunae were seen in the negative control group, and this group had significant differences with all other groups in this respect $(P<0.05)$. No significant difference was noted between the positive control and $25 \mathrm{mg} / \mathrm{kg}$ caffeine $(P=0.672)$, positive control and $50 \mathrm{mg} / \mathrm{kg}$ caffeine $(P=0.870)$, positive control and $75 \mathrm{mg} / \mathrm{kg}$ caffeine $(P=0.672), 25$ and $75 \mathrm{mg} / \mathrm{kg}$ caffeine $(P=0.870)$, or 50 and $75 \mathrm{mg} / \mathrm{kg}$ caffeine $(P=1.000)$ groups.

3.8. Effect of Caffeine on BV/TV Ratio. The micro-CT results revealed a significant difference in this regard among the five groups $(P<0.05)$. The $\mathrm{BV} / \mathrm{TV}$ ratio was minimum in the $75 \mathrm{mg} / \mathrm{kg}$ caffeine and maximum in the negative control group. The negative control group had significant differences with the other groups in this regard $(P<0.05)$. No significant difference was found between the positive control and $25 \mathrm{mg} / \mathrm{kg}$ caffeine $(P=0.395)$ and positive control and $50 \mathrm{mg} / \mathrm{kg}$ caffeine $(P=0.230)$ groups. However, the difference between the positive control and $75 \mathrm{mg} / \mathrm{kg}$ caffeine group was significant $(P=0.031)$. Pairwise comparisons of the three caffeine groups showed no significant difference $(P>0.05$, Table 3$)$.

\section{Discussion}

Several studies have assessed the effects of different medications and surgical procedures on OTM. Some studies reported that certain medications or surgical approaches enhanced OTM, while some others showed deceleration of OTM by different stimuli [33-36]. Response to orthodontic treatment with respect to the speed of OTM varies among different individuals. This variation is due to the differences in bone remodeling caused by the 
TABLE 1: Mean and standard deviations of orthodontic tooth movement (OTM) in millimeters in the five experimental groups.

\begin{tabular}{|c|c|c|c|c|c|}
\hline \multirow[t]{2}{*}{ Groups } & \multicolumn{2}{|c|}{$\begin{array}{l}\text { Distance of } \\
\text { orthodontic tooth } \\
\text { movement (OTM) } \\
\text { at the beginning of } \\
\text { the study }(\mathrm{mm})\end{array}$} & \multicolumn{2}{|c|}{$\begin{array}{l}\text { Distance of } \\
\text { orthodontic tooth } \\
\text { movement (OTM) } \\
\text { at the end of } 21 \text { days } \\
\qquad(\mathrm{mm})\end{array}$} & \multirow{2}{*}{$\begin{array}{l}\text { Differences between the beginning of the study } \\
\text { and the end of the study (mm) } \\
\text { Mean }\end{array}$} \\
\hline & Mean & SD & Mean & SD & \\
\hline Negative control & 0.20 & 0.02 & 0.22 & 0.02 & $0.02^{\mathrm{a}}$ \\
\hline Positive control & 0.20 & 0.02 & 0.45 & 0.03 & $0.19^{\mathrm{b}}$ \\
\hline Caffeine $25 \mathrm{mg} / \mathrm{kg}$ & 0.21 & 0.01 & 0.50 & 0.03 & $0.19^{\mathrm{b}}$ \\
\hline Caffeine $50 \mathrm{mg} / \mathrm{kg}$ & 0.22 & 0.02 & 0.62 & 0.03 & $0.2^{\mathrm{c}}$ \\
\hline Caffeine $75 \mathrm{mg} / \mathrm{kg}$ & 0.21 & 0.02 & 0.67 & 0.03 & $0.2^{\mathrm{c}}$ \\
\hline
\end{tabular}

${ }^{\dagger}$ Welch's one-way ANOVA test followed by Tukey's test was used. Means with the same superscript letters are not significantly different $(P>0.05)$. SD: standard deviation.
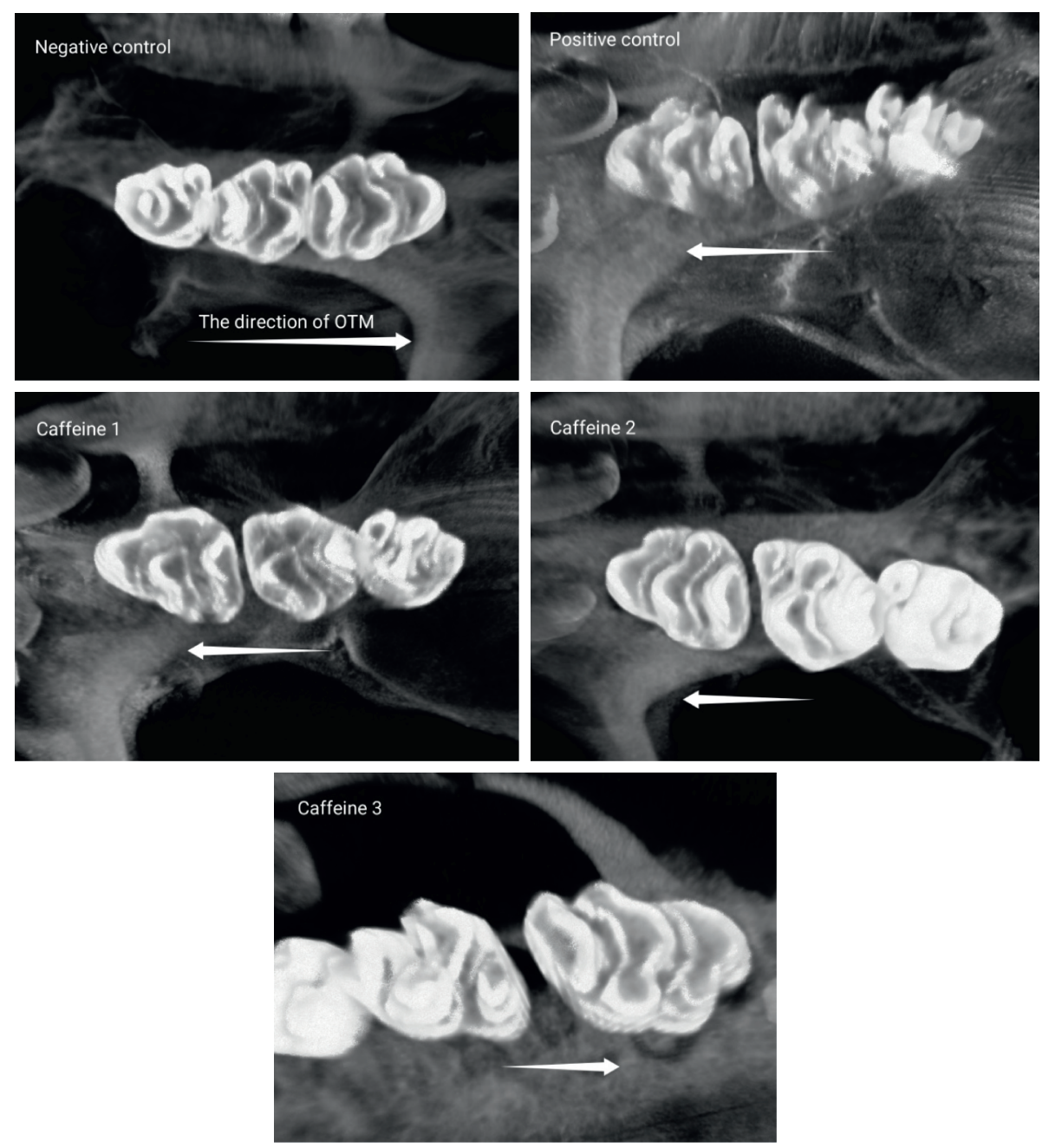

FIgUre 3: Micro-CT image $\left(1 \mu \mathrm{m}=1 \times 10^{-6} \mathrm{~m}\right.$ of orthodontic tooth movement (OTM) after 21 days of force application): negative control group (no OTM and no injection), positive group (OTM and saline injection), and experimental groups injected with 25,50 , and $75 \mathrm{mg} / \mathrm{kg}$ caffeine.

effect of different systemic factors [37]. Some materials such as triptolide were shown to significantly decrease the amount of OTM and the root resorption area in rats. Injection of triptolides can stop OTM and decrease root resorption in rats by inhibition of osteoclastogenesis.
Moreover, triptolide can positively affect osteoblastogenesis [38]. Another study showed that the level of plasma estrogen affected the speed of OTM. Estrogen inhibits osteoblastic differentiation and reinforces the apoptosis of osteoblasts and prevents alveolar resorption. 

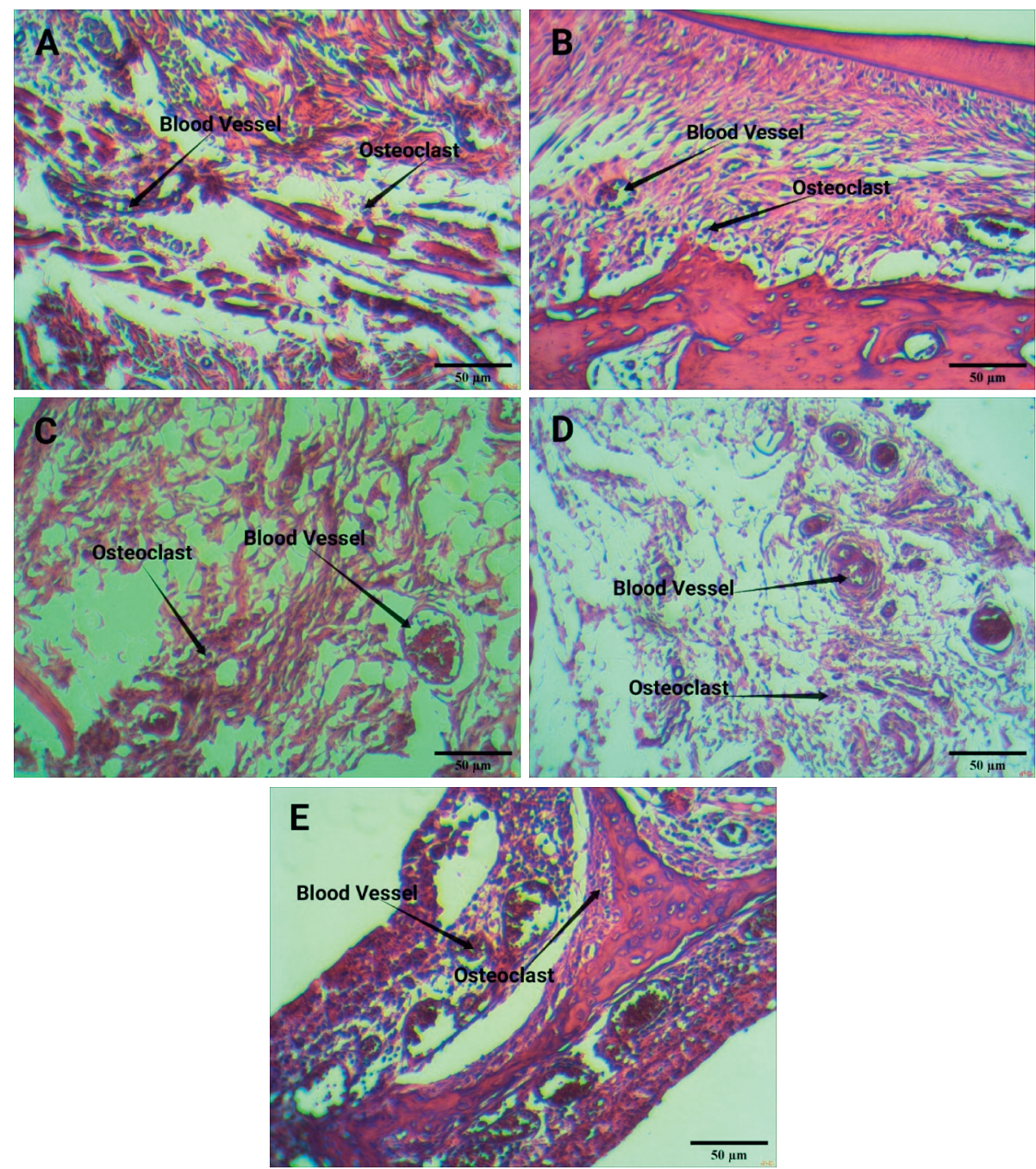

FiguRE 4: The result of HE staining. Blood vessels and osteoclasts in (a) the negative control, (b) the positive control, (c) caffeine $25 \mathrm{mg} / \mathrm{kg}$, (d) caffeine $50 \mathrm{mg} / \mathrm{kg}$, and (e) caffeine $75 \mathrm{mg} / \mathrm{kg}$. Scale bar: $50 \mu \mathrm{m}$.

TABLe 2: The mean and standard deviation of each histologic variable in the experimental groups $\left(\mathrm{mm}^{2}\right)$.

\begin{tabular}{|c|c|c|c|c|c|c|c|c|}
\hline \multirow[t]{2}{*}{ Group } & \multicolumn{2}{|c|}{$\begin{array}{c}\text { Number of } \\
\text { Howship's lacunae }\end{array}$} & \multicolumn{2}{|c|}{$\begin{array}{l}\text { Number of blood } \\
\text { vessels }\end{array}$} & \multicolumn{2}{|c|}{$\begin{array}{l}\text { Number of } \\
\text { osteoclasts }\end{array}$} & \multicolumn{2}{|c|}{$\begin{array}{l}\text { Number of root } \\
\text { resorption lacunae }\end{array}$} \\
\hline & Mean & $\mathrm{SD}$ & Mean & $\mathrm{SD}$ & Mean & SD & Mean & $\mathrm{SD}$ \\
\hline Negative control & 0.16 & 0.40 & 2.00 & 0.89 & 0.83 & 0.40 & 0.00 & 0.00 \\
\hline Positive control & 2.00 & 0.89 & 3.50 & 1.04 & 2.50 & 0.54 & 0.83 & 0.40 \\
\hline Caffeine $25 \mathrm{mg} / \mathrm{kg}$ & 2.66 & 0.81 & 3.50 & 0.54 & 3.50 & 0.83 & 1.16 & 0.40 \\
\hline Caffeine $50 \mathrm{mg} / \mathrm{kg}$ & 2.83 & 0.75 & 4.16 & 0.98 & 3.83 & 1.16 & 1.50 & 0.54 \\
\hline Caffeine $75 \mathrm{mg} / \mathrm{kg}$ & 4.16 & 0.75 & 5.66 & 0.51 & 4.00 & 0.89 & 1.50 & 0.54 \\
\hline$P$ value ${ }^{\ddagger}$ & \multicolumn{2}{|c|}{$<0.001$} & \multicolumn{2}{|c|}{$<0.001$} & \multicolumn{2}{|c|}{$<0.001$} & \multicolumn{2}{|c|}{$<0.001$} \\
\hline
\end{tabular}

${ }^{*}$ One-way ANOVA test followed by Tukey's test was used. Means with the same superscript letters are not significantly different $(P>0.05)$. SD: standard deviation.

This effect of estrogen decelerates the process of bone remodeling in OTM and decreases the rate of OTM as such [39].

This study assessed the effect of caffeine on OTM in rats. Rats are suitable laboratory animals to study bone remodeling and OTM in response to mechanical forces [40-42].
This study was the first to show that intraperitoneal injection of caffeine significantly increased OTM in rats. Caffeine is the most commonly used active medicinal agent worldwide, which is found in drinks such as coffee and tea, chocolate products, and some medications. Consumption of energy drinks containing high amounts of caffeine has greatly 
TABle 3: Mean BV/TV ratios in the study groups.

\begin{tabular}{ccc}
\hline \multicolumn{2}{c}{$\begin{array}{c}\text { Bone volume-to-total } \\
\text { volume ratio (BV/TV, \%) } \\
\text { SD }\end{array}$} & Mean \\
\hline 3.6 & 74.2 & Nroups \\
4.8 & 67.7 & Pogative control \\
2.8 & 64.0 & Caffeine 1 \\
3.4 & 63.2 & Caffeine 2 \\
4.2 & 61.2 & Caffeine 3 \\
& $<0.001$ & $P$ value \\
\hline
\end{tabular}

FOne-way ANOVA test followed by Tukey's test was used. Means with the same superscript letters are not significantly different $(P>0.05)$.

increased in the recent years [43]. An animal study showed that brewed coffee increased the level of RANKL and OPG and enhanced OTM. Thus, brewed coffee can effectively accelerate the process of orthodontic treatment [2]. Another study showed that caffeine effectively increased the level of PGE2. PGE2 serves as a stimulant for the formation of RANKL in osteoblasts and increases the number of osteoclasts and OTM [43].

The results of the present study revealed that orthodontic forces stimulated the osteoclasts and angiogenesis. Also, injection of 25,50 , and $75 \mathrm{mg} / \mathrm{kg}$ caffeine along with orthodontic force application further increased the number of osteoclasts and blood vessels. Although the difference in this respect was not significant among different doses of caffeine, caffeine injection eventually increased OTM. Increasing the caffeine dosage increased OTM. Histological assessments revealed that injection of caffeine increased the number of osteoclasts, Howship's lacunae, and blood vessels. However, it did not significantly increase the number of root resorption lacunae. The increase in the number of osteoclasts due to caffeine injection was in agreement with a previous report in this regard [16]. Micro-CT indicated a lower BV/ TV ratio in the caffeine groups, which was in agreement with the increase in the number of osteoclasts. Nonetheless, several complex factors are involved in the measurement of the amount of OTM such as deformation of the appliance while chewing, mesial drift of the second molar, and cranial growth during the study period [29].

In this study, all measurements were made by the same examiner to eliminate interobserver errors, which was a strength of this study.

This study had some limitations. It was an animal study with limited sample size. The findings of animal studies should be further confirmed by clinical human studies. Ethically, a minimum acceptable number of laboratory animals should be used in animal studies, which limits the generalizability of the results. Human studies with larger sample size are required to assess the effect of caffeine on OTM over long courses of treatment.

\section{Conclusion}

This animal study indicated that caffeine can accelerate OTM in rats, and this effect was fortified by increasing the caffeine dosage. Further investigations are required to elucidate the mechanisms involved in this effect. Generalization of the results of animal studies to humans should be done with caution. Given that the results are confirmed, the skeletal effects of caffeine should also be taken into account by orthodontists in orthodontic treatment planning.

\section{Data Availability}

No data were used to support this study.

\section{Ethical Approval}

The ethics committee of Kermanshah University of Medical Sciences approved this study (IR.KUMS.REC.1397.724).

\section{Consent}

All authors consented to the publication of this manuscript.

\section{Conflicts of Interest}

The authors declare no conflicts of interest.

\section{Authors' Contributions}

All authors conceptualized and designed the research, contributed to acquisition, and performed analysis of data, wrote the manuscript, translated to English, participated in manuscript revision, and approved the final manuscript.

\section{Acknowledgments}

This work was supported by a grant from the Kermanshah University of Medical Sciences, Kermanshah, Iran (Grant no. 97684).

\section{References}

[1] B. Sun, Y. Wen, X. Wu, Y. Zhang, X. Qiao, and X. Xu, "Expression pattern of YAP and TAZ during orthodontic tooth movement in rats," Journal of Molecular Histology, vol. 49, no. 2, pp. 123-131, 2018.

[2] I. B. Narmada, "The role of rankl and opg in alveolar bone remodeling and improvement of orthodontic tooth movement post coffee brew administration," Journal of International Dental and Medical Research, vol. 10, no. 1, p. 84, 2017.

[3] A. Golshah, "Gingivitis effectiveness of emulgel containing $2 \%$ resveratrol in orthodontic patients: an 8-week randomized clinical trial," International Journal of Dentistry, vol. 2021, Article ID 6615900, 7 pages, 2021.

[4] M. Shirazi, H Vaziri, B Salari, P Motahhari, S EtemadMoghadam, and A. R Dehpour, "The effect of caffeine on orthodontic tooth movement in rats," Iranian journal of basic medical sciences, vol. 20, no. 3, pp. 260-264, 2017.

[5] A. Golshah, "Effect of methotrexate injection on orthodontic tooth movement: an experimental study on rats," International Journal of Dentistry, vol. 2021, Article ID 8451522, 8 pages, 2021.

[6] F. Ghorbani, "The inhibitory Effects of nucleosides. Nicotinamide adenine dinucleotide," Adenosine, vol. 5, pp. 182-198. 
[7] A. Miresmaeili, N Mollaei, R Azar, N Farhadian, and K Mani Kashani, "Effect of dietary vitamin C on orthodontic tooth movement in rats," Journal of Dentistry (Tehran, Iran), vol. 12, no. 6, pp. 409-13, 2015.

[8] Y. Chen, X. X Wang, B. J Zhao, J Bu, Y. R Su, and J Zhang, "Effects of icariin on orthodontic tooth movement in rats," International Journal of Clinical and Experimental Medicine, vol. 8, no. 6, pp. 8608-16, 2015.

[9] Y. Rahmatia, "Weighted correlation network analysis of multiple sclerosis: identifying key genes involved in disease progress," Journal of Computational Chemistry and Molecular Modelling, vol. 4.

[10] J. Yi, "Drinking coffee may help accelerate orthodontic tooth movement," Dental Hypotheses, vol. 3, no. 2, p. 72, 2012.

[11] S. S. Bhat, Drug Induced Orthodontic Tooth Movement: A Comprehensive Review.

[12] T. N. Bartzela and J. C. Maltha, "Medication effects on the rate of orthodontic tooth movement," in Biology of Orthodontic Tooth Movement, pp. 133-159, Springer, 2016.

[13] S. Krishnan and A. K. S. Saravana Pandian, "Effect of bisphosphonates on orthodontic tooth movement-an update," Journal of Clinical and Diagnostic Research: Journal of Clinical and Diagnostic Research, vol. 9, no. 4, p. ZE01, 2015.

[14] J. dePaula and A. Farah, "Caffeine consumption through coffee: content in the beverage, metabolism, health benefits and risks," Beverages, vol. 5, no. 2, p. 37, 2019.

[15] J. P. Bezerra, L. R. F. da Silva, V. A. de Alvarenga Lemos, P. M. Duarte, and M. F. Bastos, "Administration of high doses of caffeine increases alveolar bone loss in ligature-induced periodontitis in rats," Journal of Periodontology, vol. 79, no. 12, pp. 2356-2360, 2008.

[16] J. Yi, B. Yan, M. Li et al., "Caffeine may enhance orthodontic tooth movement through increasing osteoclastogenesis induced by periodontal ligament cells under compression," Archives of Oral Biology, vol. 64, pp. 51-60, 2016.

[17] A. E. Ratajczak, A. Szymczak-Tomczak, A. Zawada, A. M. Rychter, A. Dobrowolska, and I. Krela-Kaźmierczak, "Does drinking coffee and tea affect bone metabolism in patients with inflammatory bowel diseases?" Nutrients, vol. 13, no. 1, p. 216, 2021.

[18] Y. H. Tsuang, J. S Sun, L. T Chen, S. C Sun, and S. C Chen, "Direct effects of caffeine on osteoblastic cells metabolism: the possible causal effect of caffeine on the formation of osteoporosis," Journal of Orthopaedic Surgery and Research, vol. 1, no. 1, pp. 7-10, 2006.

[19] P. B. Rapuri, J. C. Gallagher, H. K. Kinyamu, and K. L. Ryschon, "Caffeine intake increases the rate of bone loss in elderly women and interacts with vitamin D receptor genotypes," American Journal of Clinical Nutrition, vol. 74, no. 5, pp. 694-700, 2001.

[20] W. Sakamoto, J. Nishihira, K. Fujie et al., "Effect of coffee consumption on bone metabolism," Bone, vol. 28, no. 3, pp. 332-336, 2001.

[21] P. Nawrot, S. Jordan, J. Eastwood, J. Rotstein, A. Hugenholtz, and M. Feeley, "Effects of caffeine on human health," Food Additives \& Contaminants, vol. 20, no. 1, pp. 1-30, 2003.

[22] R. Liu, "Biomechanical interfaces of corticotomies on periodontal tissue remodeling during orthodontic tooth movement," Coatings, vol. 11, no. 1, p. 1, 2021.

[23] N. Percie du Sert, A. Ahluwalia, S. Alam et al., "Reporting animal research: explanation and elaboration for the ARRIVE guidelines 2.0," PLoS Biology, vol. 18, no. 7, Article ID e3000411, 2020.
[24] S. Mahmoudzehi, "The neuroprotective effects of alcoholic extract of Levisticum officinale on alpha motoneurons degeneration after sciatic nerve compression in male rats," International Journal of Medical Research \& Health Sciences, vol. 5, pp. 647-653, 2016.

[25] X.-C. Liu, X.-X. Wang, L.-N. Zhang, F. Yang, F.-J. Nie, and J. Zhang, "Inhibitory effects of resveratrol on orthodontic tooth movement and associated root resorption in rats," Archives of Oral Biology, vol. 111, Article ID 104642, 2020.

[26] N. Alhashimi, L Frithiof, P Brudvik, and M Bakhiet, "CD40-CD40L expression during orthodontic tooth movement in rats," The Angle Orthodontist, vol. 74, no. 1, pp. 100-105, 2004.

[27] J. Lu, Y. Duan, M. Zhang, M. Wu, and Y. Wang, "Expression of Wnt3a, Wnt10b, $\beta$-catenin and DKK1 in periodontium during orthodontic tooth movement in rats," Acta Odontologica Scandinavica, vol. 74, no. 3, pp. 217-223, 2016.

[28] J. C. Karras, J. R. Miller, J. S. Hodges, J. P. Beyer, and B. E. Larson, "Effect of alendronate on orthodontic tooth movement in rats," American Journal of Orthodontics and Dentofacial Orthopedics, vol. 136, no. 6, pp. 843-847, 2009.

[29] L. Guan, S. Lin, W. Yan, L. Chen, and X. Wang, "Effects of calcitonin on orthodontic tooth movement and associated root resorption in rats," Acta Odontologica Scandinavica, vol. 75, no. 8, pp. 595-602, 2017.

[30] H. AlSwafeeri, W. ElKenany, M. Mowafy, and S. Karam, "Effect of local administration of simvastatin on postorthodontic relapse in a rabbit model," American Journal of Orthodontics and Dentofacial Orthopedics, vol. 153, no. 6, pp. 861-871, 2018.

[31] S. Akbulut, A. Yagci, A. H. Yay, and B. Yalcin, "Experimental investigation of effects of platelet-rich plasma on early phases of orthodontic tooth movement," American Journal of Orthodontics and Dentofacial Orthopedics, vol. 155, no. 1, pp. 71-79, 2019.

[32] L. A. Feldkamp, L. C. Davis, and J. W. Kress, "Practical conebeam algorithm," Journal of the Optical Society of America A, vol. 1, no. 6, pp. 612-619, 1984.

[33] H. Hermizi, "Nicotine impaired bone histomorphometric parameters and bone remodeling biomarkers in Sprague-Dawley male rats," Ann Microscopy, vol. 7, pp. 10-24, 2007.

[34] C. L. Henemyre, D. Scales, S. D. Hokett et al., "Nicotine stimulates osteoclast resorption in a porcine marrow cell model," Journal of Periodontology, vol. 74, no. 10, pp. 1440-1446, 2003.

[35] M. Norazlina, H. Hermizi, O. Faizah, A. S. Nazrun, M. Norliza, and S. Ima-Nirwana, "Vitamin E reversed nicotine-induced toxic effects on bone biochemical markers in male rats," Archives of Medical Science, vol. 4, no. 4, pp. 505-512, 2010.

[36] H. Hapidin, F. Othman, I.-N. Soelaiman, A. N. Shuid, D. A. Luke, and N. Mohamed, "Negative effects of nicotine on bone-resorbing cytokines and bone histomorphometric parameters in male rats," Journal of Bone and Mineral Metabolism, vol. 25, no. 2, pp. 93-98, 2007.

[37] N. Murtaza, W. U. Hamid, A. Shamim, S. Hussain, M. Azeem, and M. N. Sadiq, "Combined effect of nicotine and caffeine on orthodontic tooth movement in rats," Journal of Islamabad Medical \& Dental College, vol. 9, no. 2, pp. 109-114, 2020.

[38] F. Yang, X. X. Wang, D. Ma et al., "Effects of triptolide on tooth movement and root resorption in rats," Drug Design, Development and Therapy, vol. 13, pp. 3963-3975, 2019. 
[39] L. Deng and Y. Guo, "Estrogen effects on orthodontic tooth movement and orthodontically-induced root resorption," Archives of Oral Biology, vol. 118, Article ID 104840, 2020.

[40] K. Yamasaki, "The role of cyclic AMP, calcium, and prostaglandins in the induction of osteoclastic bone resorption associated with experimental tooth movement," Journal of Dental Research, vol. 62, no. 8, pp. 877-881, 1983.

[41] B. Tengku, "Effect of a static magnetic field on orthodontic tooth movement in the rat," The European Journal of Orthodontics, vol. 22, no. 5, pp. 475-487, 2000.

[42] Y. Ren, J. C. Maltha, and A. M. Kuijpers-Jagtman, "The rat as a model for orthodontic tooth movement--a critical review and a proposed solution," The European Journal of Orthodontics, vol. 26, no. 5, pp. 483-490, 2004.

[43] H. Herniyati, I. B. Narmada, and L. S. Devi, Caffeine Increases PGE2 Levels at Compression and Tension Areas during Orthodontic Tooth Movement, 2018. 